\title{
Agricultura urbana: um olhar a partir da agroecologia e da agricultura orgânica'
}

Mariana Barbosa de Souza² Ana Claudia Guske ${ }^{3}$

\section{Resumo}

Este estudo visa trazer à discussão o conceito de agricultura urbana a partir da agroecologia e da agricultura orgânica. Como mecanismo para aprofundar a discussão, a pesquisa levou em consideração o fato de que, no âmbito da agricultura urbana, enquanto campo interdisciplinar de reflexão, encontram-se conceitoschave, como agricultura urbana e periurbana, agroecologia e agricultura orgânica. Assim, este estudo visa trazer à discussão os conceitos mencionados, considerando a sua relevância, especificamente em tempos de mudanças climáticas e ambientais globais, bem como responder à questão que o embasa. Para a realização dessa proposta, o presente estudo apresenta uma breve revisão teórica dos conceitos mencionados bem como o resultado de um estudo exploratório, buscando, a partir de um levantamento bibliográfico e documental, uma resposta à indagação que se refere à possibilidade de a agricultura urbana, associada à agroecologia e à agricultura orgânica, contribuir para o desenvolvimento regional.

Palavras-chave: Agricultura urbana. Agricultura periurbana. Agroecologia. Agricultura orgânica.

\section{Abstract}

This study aims to bring to the discussion the concept of urban agriculture from agroecology and organic agriculture. As a mechanism to deepen the discussion, the survey took into consideration that in the context of urban agriculture as an interdisciplinary field of reflection, are key concepts such as urban and peri-urban agriculture, agro-ecology and organic farming. Thus, this study aims to bring to the discussion the concepts mentioned, considering their relevance, specifically in times of global climate and environmental changes, as well as, answer the question that bases this study. To accomplish this proposal, the present study presents a brief theoretical review of the concepts mentioned and the result of an exploratory study seeking a response to the question that refers to the possibility of urban

\footnotetext{
${ }^{1}$ Uma versão preliminar deste artigo foi publicada nos anais do 1 ㅇ Seminário Nacional de Desenvolvimento Regional: sustentabilidade socioeconômica e ambiental no contexto regional, realizado em abril de 2016, nas Faculdades Integradas de Taquara (Faccat/RS).

${ }^{2}$ Mestre em Desenvolvimento Regional. Doutoranda em Desenvolvimento Regional no Programa de Pós-Graduação em Desenvolvimento Regional da Universidade de Santa Cruz do Sul (Unisc). marisouza_10@hotmail.com

${ }^{3}$ Mestranda em Desenvolvimento Regional no Programa de Pós-Graduação em Desenvolvimento Regional da Universidade de Santa Cruz do Sul (Unisc). anaguske@mx2.unisc.br
} 
agriculture, associated with agroecology and organic agriculture, to contribute For regional development, based on a bibliographical and documentary survey.

Keywords: Urban agriculture. Peri-urban agriculture. Agroecology. Organic agriculture.

\section{Introdução}

O presente estudo é resultado de um esforço de reflexão acerca de conteúdos que associam aspectos da agricultura urbana com a agroecologia e com a agricultura orgânica, na intenção de identificar e compreender possíveis relações entre elas, e discussões sobre desenvolvimento rural e regional. A partir de uma revisão bibliográfica referente aos conceitos de agricultura urbana, agricultura periurbana e agroecologia, busca-se explicitar, de forma simples, as possíveis relações entre esses conceitos.

A temática da agricultura urbana abrange diversas facetas que implicam o entendimento das dimensões sociais, políticas, econômicas e culturais, entre outras. As relações existentes entre meio ambiente, desenvolvimento rural e cultura, mormente a forma como a cultura se torna um elemento importante nas estratégias de desenvolvimento, demonstram, no global, uma condição de legitimação das esferas regional e local.

A questão de pesquisa se refere à possibilidade de a agricultura urbana, associada à agroecologia e à agricultura orgânica, contribuir para o desenvolvimento regional, conduzida pela necessidade de compreender o tema e de identificar a sua importância para esse tipo de desenvolvimento. Há muitas propostas de estudo acerca da agricultura urbana, entretanto ainda incipientes e com necessidade de fortalecimento. Nesse sentido, o objetivo deste estudo é descrever a importância da agricultura urbana sob o prisma da agroecologia e da agricultura orgânica.

O método de pesquisa utilizado foi o dedutivo, partindo-se de um referencial teórico que possui relação com o estudo proposto. A pesquisa é aplicada e, no tocante aos objetivos, é exploratória e descritiva. O estudo é exploratório porque apresenta maior proximidade com uma indagação a ser esclarecida a partir de levantamento bibliográfico e documental. Também é descritiva, visto que tem como objetivo descrever as principais características do elemento estudado, bem como criar ligações entre variáveis. Marconi e Lakatos (2003) afirmam que pesquisas exploratórias e descritivas, quando combinadas, visam descrever detaIhadamente fenômenos. Igualmente, depois de utilizar os métodos de pesquisa bibliográfico e documental, fez-se uma análise de conteúdo.

Pressupõe-se que a agricultura urbana poderá ser útil para o desenvolvimento regional no atual contexto do processo mundial de globalização. A justificativa para estudar a agricultura urbana é a da necessidade de se conhecer o tema e sua importância para o desenvolvimento regional. Este estudo possui um recorte específico, porém não se esgota nele. Outras relações com a agricultura 
urbana podem ser objeto de estudos futuros, tendo em vista a importância da temática.

O estudo está organizado em seções, entre as quais se inclui esta introdução e, a seguir, outras duas, que apresentam os conceitos afeitos à temática, tais como os de agroecologia e de agricultura orgânica, e, em seguida, os de agricultura urbana e periurbana. Depois, apresentam-se os resultados do estudo, e, por fim, as considerações finais.

\section{Agroecologia e agricultura orgânica}

Buscando conceituar o que é agroecologia, Caporal e Costabeber (2004) afirmam que, para isso, é necessário identificar, primeiramente, o que não é agroecologia. Assim, pode-se evitar uma visão reducionista do termo e usá-lo para de fato embasar discussões e debates que envolvam o homem e sua qualidade de vida, ou, ainda, o desenvolvimento rural sustentável. Então, destacam que o termo agroecologia não tem um conceito determinado, visto que os estudos que se debruçam sobre ele são recentes. Porém, tem-se que a agroecologia passou a existir a partir dos anos de 1980. O saber fazer das comunidades campesinas foi determinante para o surgimento do termo. Ademais, somado a isso, tem-se a agronomia e a ecologia, as quais relacionaram o saber dos camponeses ao meio ambiente e a uma agricultura sustentável, responsável pelo bem do homem.

Nesse sentindo, Caporal (2009) declara que:

Ao contrário das formas compartimentadas de ver e estudar a realidade, ou dos modos isolacionistas das ciências convencionais, baseadas no paradigma cartesiano, a Agroecologia busca integrar os saberes históricos dos agricultores com os conhecimentos de diferentes ciências, permitindo, tanto a compreensão, análise e crítica do atual modelo do desenvolvimento e de agricultura, como o estabelecimento de novas estratégias para o desenvolvimento rural e novos desenhos de agriculturas mais sustentáveis, desde uma abordagem transdisciplinar (CAPORAL, 2009, p. 15).

Importa mencionar que, na agroecologia, há uma relação embasada no equilíbrio, ou seja, hão de estar interagindo, de forma harmoniosa, as plantas, o solo, a energia solar, a umidade, bem como outros organismos existentes. Somente assim será possível que o agrossistema se torne produtivo. Essa tática de harmonização é permitida por meio do manejo de sistemas produtivos complexos e distintos, os quais ensejam a mantença de mais de um cultivo anual, associado a criações (ALTIERI, 1998).

Envolvendo a ideia de equilíbrio, tem-se que a base da produção agroecológica é caracterizada pelo uso de ferramentas tecnológicas que respeitam a natureza, a fim de se preservar, ou, até mesmo, modificar minimamente o ambiente, bem como as condicionantes de equilíbrio existentes nos organismos que atuam nesse processo de produção. Diante dessas características, distintos segmentos de produção agrícola, que não o industrial, estão sendo desenvolvidos, sendo que o que recebe maior destaque é o da agricultura orgânica, diante de 
sua difusão (ASSIS; ROMEIRO, 2002). Ainda, de acordo com Caporal, Costabeber e Paulus (2005, p. 2), a agroecologia está apoiada em ensinamentos de diferentes disciplinas científicas: "Física, a Economia Ecológica e Ecologia Política, a Agronomia, a Ecologia, a Biologia, a Educação e Comunicação, a História, a Antropologia, a Sociologia e os Estudos Camponeses, apenas para citar alguns exemplos".

Nesse sentido, a agroecologia, aliando conhecimentos de diversas áreas, tem como foco principal o equilíbrio biológico, o uso responsável do meio ambiente. Caporal e Costabeber (2004, p. 9) afirmam que:

Em síntese, é preciso ter clareza que a agricultura ecológica e a agricultura orgânica, entre outras denominações existentes, conceitual e empiricamente, em geral, são o resultado da aplicação de técnicas e métodos diferenciados dos pacotes convencionais, normalmente estabelecidas de acordo e em função de regulamentos e regras que orientam a produção e impõem limites ao uso de certos tipos de insumos e a liberdade para o uso de outros.

A agricultura orgânica, assim, tem por escopo criar sistemas de produção alicerçados em tecnologias de processos, ou seja, procedimentos que, em conjunto, envolvem a planta, o solo, as condições do clima, a fim de produzir um alimento saudável, o qual mantenha as características originais, como o sabor, e satisfaça às expectativas do consumidor (PENTEADO, 2000).

Quanto às expectativas do consumidor, Canuto (1998) declara que elas podem influenciar o mercado e suas características, bem como as necessidades de consumo, as quais influem na tecnologia de produção, acabando por reduzir métodos utilizados e minimizar as questões de cunho ecológico.

Essa nova ideia do que é agricultura orgânica, focalizando no mercado de produtos orgânicos, favorece a fixação de sistemas de produção com base em tecnologias de produtos. Ou seja, são sistemas que buscam evitar o uso total de sintéticos, pesticidas, bem como de reguladores de crescimento e aditivos na alimentação de animais, como é requerido pelo mercado. Portanto, segue a mesma lógica da produção industrial (AQUINO; ASSIS, 2007).

No caso do presente estudo, a agricultura orgânica, em regiões urbanas, é guiada pelos princípios norteadores da agroecologia, a qual faz uso racional da natureza, cultuando o seu equilíbrio. A agricultura orgânica baseia-se nos bons níveis de produtividade, impedindo os riscos de contaminação química tanto àqueles que cultivaram a agricultura no meio urbano como aos seus consumidores. Igualmente, ela é catalisadora do desenvolvimento regional, porquanto alia conhecimentos, saberes, culturas, bem como experiências locais.

\section{Agricultura urbana e agricultura periurbana}

O conceito de agricultura urbana, assim como o de agroecologia, necessita de evolução, embora não seja um termo recente. O termo agricultura urbana vem sendo usado amplamente nos meios acadêmicos e, mais recentemente, nos meios de comunicação. Sua popularização faz com que seja ainda mais urgente e 
importante sua definição, bem como seja especificado seu conceito, a fim de que se torne um instrumento útil para a compreensão da temática. Ainda, de acordo com Mougeot (2000, p. 2):

[...] devemos perguntar se a agricultura urbana é realmente o que chamamos, ou assim queremos chamar, ou o que percebemos na realidade. A definição geral deve levar-nos a um sistema ou construção conceitual, a uma estrutura de compartimentos interconectados baseados nas experiências do mundo real.

O significado de agricultura urbana diz respeito ao local - dentro e ao redor das cidades ou áreas urbanas -, aos espaços. A área que possui alguma atividade agrícola inserida nas cidades é chamada de intra-urbana e pode abranger qualquer tipo de área, individual ou coletiva, podendo envolver ainda vias públicas, praças, parques e áreas que não estão sendo utilizadas, como lotes e terrenos baldios. A Figura 1, a seguir, apresenta um exemplo de agricultura orgânica intra-urbana, utilizada na Colômbia.

\section{Figura 1 - Agricultura intra-urbana}

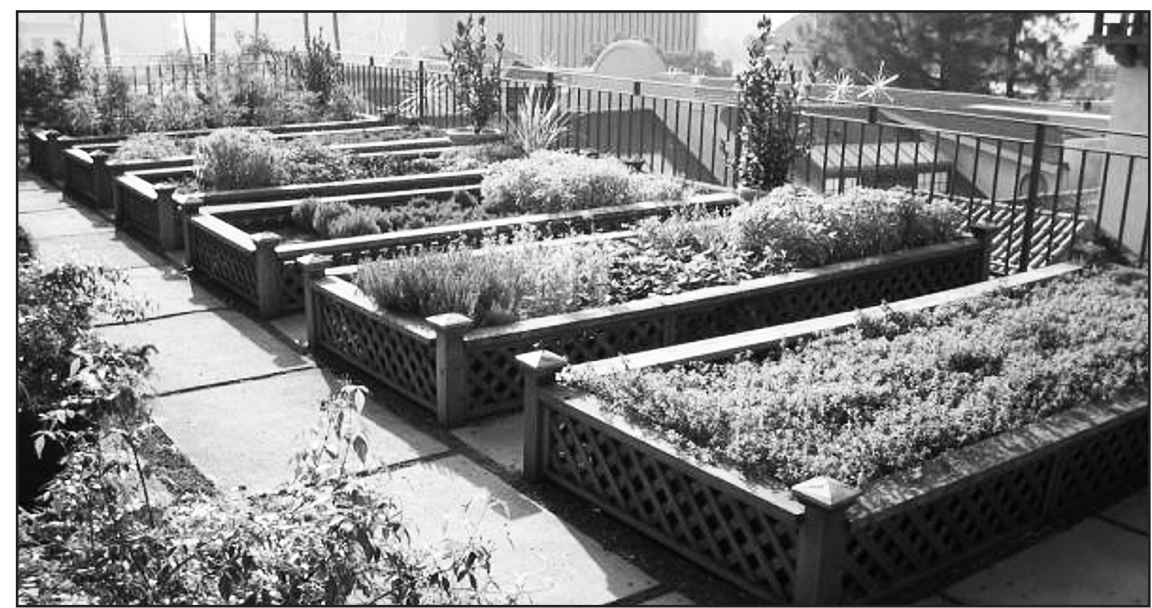

Fonte: Orgánicos de Colombia (2015).

A chamada área periurbana é mais complexa, visto que seu conceito não está associado à localização. Ela deve estar perto de cidades, entretanto o limite pode envolver 10 e $90 \mathrm{~km}$, variando quanto ao desenvolvimento de estradas e custos de transportes. A agricultura periurbana pode interferir, quando próxima a áreas rurais, na própria agricultura, podendo associar trabalho rural com trabalho não rural. Muitas áreas, antes consideradas rurais, atualmente são consideradas áreas de agricultura periurbana (MACHADO; MACHADO, 2002).

Importante destacar que atividades tipicamente urbanas começaram a avançar sobre espaços que, anteriormente, eram destinados e utilizados pela agricultura. A convivência entre problemas tipicamente rurais e problemas de cunho urbano, em um mesmo espaço, fez com que a realidade periférica das 
cidades e dos espaços urbanos se tornasse ainda mais complexa. Problemas de cunho social, bem como de poluição ambiental, passaram a ser grandes desafios no mundo moderno. A Figura 2, abaixo, retrata um exemplo de agricultura periurbana.

Figura 2 - Agricultura periurbana

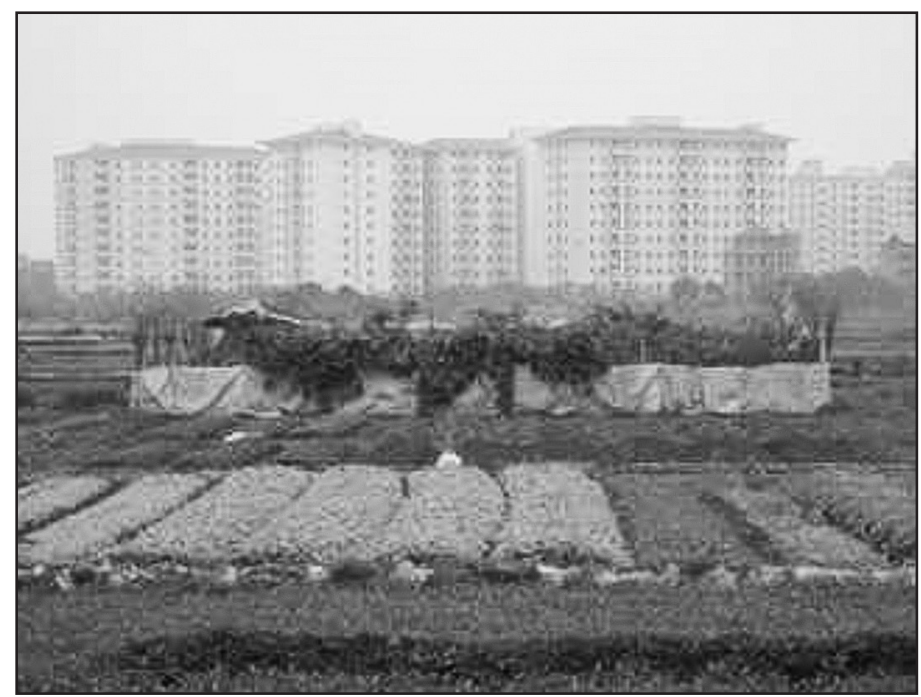

Fonte: Instituto Ecoacao (2015).

Machado e Machado (2002, p. 12) afirmam que, além dos desafios mencionados alhures, a usurpação de áreas antes rurais por áreas periurbanas envolve também outras questões, entre as quais:

O lixo e a violência passaram a fazer parte da rotina dessas áreas, existindo certa revolta pela perda de terras, de atividades e principalmente de alimentos. A atividade agrícola periurbana passa, então, a ser de fundamental importância nessas áreas para promover maior equilíbrio social, proteção ambiental e pela segurança alimentar, esperando-se, então, um desenvolvimento periférico sustentável e menos agressivo.

O desenvolvimento da agricultura em áreas periurbanas está associado ao próprio desenvolvimento das cidades, de como se dá o seu crescimento demográfico, bem como o seu desenvolvimento econômico. Percebe-se, assim, uma reconfiguração dos espaços urbanos mediante novos usos do solo, novas estruturas populacionais, novas práticas sociais, dentre outras possibilidades. Inclusive, para alguns autores como Ferreira e Castilho (2007), este entendimento passa a ser assertivo, ou seja, a densidade populacional está permitindo a propagação da agricultura urbana.

Dessa forma, a agricultura urbana e periurbana encontra-se como uma alternativa para os problemas criados pelo aumento e intensidade das cidades, mormente os que têm relação com alimentação, saúde, meio ambiente equili- 
brado, bem como geração de renda. Quando a produção da agricultura urbana é consumida pela população local, mediante comercialização em mercados da região em que é produzida, grande parte das pessoas beneficia-se do consumo de alimentos frescos e saudáveis. A agricultura urbana pode contribuir de forma eficiente para a segurança alimentar e nutricional das pessoas.

Da mesma forma, as áreas urbanas estão cada vez mais presentes no mundo. No Brasil, a partir da década de 1980, a urbanização tornou-se um processo intenso, passando a caracterizar de forma marcante o território brasileiro. Atualmente, já existem novas nomenclaturas, como megalópoles, para dar conta de cidades que abrigam uma quantidade expressiva de habitantes.

Com um mundo cada vez mais urbano, questões relacionadas à subsistência humana vêm à tona: como dar conta de alimentar uma população que se estabelece principalmente em aglomerações urbanas?

Weid (2004, p. 1) afirma:

No Brasil, se o volume consumido pela população como um todo fosse repartido de forma igualitária, a ingestão diária por pessoa, incluindo todos os tipos de alimento, seria de pouco mais de 900 gramas (IBGE, 2003). O consumo de menos de um quilo por dia pode estar no limite da suficiência, em uma dieta bem equilibrada, para um trabalhador intelectual bastante espartano, mas dificilmente cobrirá as necessidades de calorias e proteínas de um trabalhador braçal ou um de adolescente em idade de crescimento. Conclui-se, portanto, que a distribuição desigual de alimentos no mundo é o fator que gera as situações de fome e de insuficiência nutricional. Já no Brasil, ao mesmo problema distributivo associa-se uma oferta total insuficiente para o atendimento da demanda da população.

Diante da problemática diacrônica insuficiência/má-distribuição de alimentos no Brasil, a agricultura urbana coloca-se como uma alternativa que reúne agricultura orgânica, desenvolvimento rural, cidade sustentável e meio ambiente equilibrado. Mougeot (2005, p. 5), quanto à distribuição dos produtos produzidos pela agricultura urbana, afirma que

A maioria das definições de agricultura urbana inclui a produção agrícola tanto para autoconsumo como para algum tipo de comércio. Geralmente ambos os objetivos são visados pelos produtores, ou nos lares onde se pratica a agricultura urbana. Algumas pesquisas econômicas recentes têm focalizado a produção orientada especificamente para a exportação, e nos ajudam a entender melhor o desempenho econômico da agricultura urbana e suas vantagens comparativas com relação a outras fontes de abastecimento, tanto do ponto de vista do produtor como do consumidor.

No Brasil, a agricultura urbana e periurbana deve ser entendida a partir das mudanças existentes na sociedade atual, levando-se em consideração o fenômeno da globalização, o desenvolvimento das tecnologias de informação, a criação de um sistema agroalimentar que exerça influência nos hábitos alimentares, bem como a preponderância de monoculturas no meio rural (RODRIGUES, 2009).

Santos (1997, p. 16) afirma que existem quatro formas de produção da 
globalização. Uma delas é o globalismo localizado, o qual, de acordo com o autor,

consiste no impacto específico de práticas e imperativos transnacionais nas condições locais, as quais são, por essa via, desestruturadas e reestruturadas de modo a responder a esses imperativos transnacionais. Tais globalismos localizados incluem: enclaves de comércio livre ou zonas francas; desflorestamento e destruição maciça dos recursos naturais para pagamento da dívida externa; uso turístico de tesouros históricos, lugares ou cerimónias religiosos, artesanato e vida selvagem; dumping ecológico ('compra' pelos países do Terceiro Mundo de lixos tóxicos produzidos nos países capitalistas centrais para gerar divisas externas); conversão da agricultura de subsistência em agricultura para exportação como parte do 'ajustamento estrutural'; etnicização do local de trabalho (desvalorização do salário pelo facto de os trabaIhadores serem de um grupo étnico considerado 'inferior' ou 'menos exigente').

Como Santos (1997) declara, cada vez mais a agricultura convencional vira alvo de grandes grupos do agronegócio. Essa assertiva serve para aumentar ainda mais a importância dada à agricultura urbana como alternativa ao processo de globalização, ou, como Boaventura mesmo chama, "globalismo localizado".

Na medida em que se apresentam como indutores hegemônicos da produção no mundo, os enjambres do capitalismo globalizado operam como catalisadores de espaços regionais. Estes provocam uma série de visões diferentes sobre os fatores que ocasionam o aumento da agricultura urbana (BAUMANN, 1999).

Assim, a agricultura urbana se apresenta como um processo de fortalecimento regional diante do capitalismo globalizado, principalmente por sua influência, ou seja, ela ocasiona o fortalecimento da região, o que se torna importante em tempos de globalização e espraiamento da hegemonia do capital.

\section{A relação entre a agricultura urbana e a agroecologia}

Iniciadas as pesquisas de cunho documental e bibliográfico, objetivou-se realizar a conceituação e fundamentação teórica do presente trabalho, bem como do atual estado da arte. Assim, para se responderem às primeiras indagações, palavras-chave foram buscadas, tais como agricultura urbana e periurbana, bem como agroecologia. Dessa forma, foram encontrados documentos, artigos e sites que versavam sobre a temática, e teóricos como Caporal, Costabeber e Paulus.

Constatou-se, então, que a agricultura urbana pode ser uma alternativa à elevação da urbanização mundial e do consequente e possível esvaziamento do meio rural. Igualmente, outros resultados podem surgir, como a qualidade dos alimentos ingeridos, visto que, aliados à agroecologia, são despidos de agrotóxicos, ou recebem o mínimo de insumos possíveis. Ainda, esse tipo de agricultura pode ser uma fonte alternativa de renda das famílias envolvidas, gerando, até mesmo, um senso de comunidade ante essa agregação.

A agricultura urbana pode envolver produção além dos vegetais. A criação de animais também pode ser objeto desse sistema. Muitas atividades podem ser 
combinadas, desde a produção de vegetais e frutas até a criação de animais.

Aquino e Assis (2007, p. 143) afirmam que

O sistema agrícola urbano pode ser uma combinação de muitas atividades diferentes, incluindo desde a horticultura e o cultivo de cereais como milho e feijão à integração com a produção animal, aproveitando-se restos vegetais na alimentação destes, através de compostagem isoladamente ou em conjunto com o esterco oriundo das criações.

Após obtenção e reunião de todas as informações e dados necessários, foram realizadas as análises dos resultados e elaboradas as considerações apresentadas neste estudo. A partir da coleta dos dados bibliográficos e documentais, passou-se a conceituar agroecologia e agricultura urbana e periurbana. Pode-se perceber que a primeira é recente, tendo os anos de 1980 como marco de início dos seus estudos. Os saberes das comunidades oriundas do campo foram essenciais para que se estudasse o que é agroecologia. Também tiveram importância para a agronomia e para a ecologia, porque relacionaram saberes campesinos, desenvolvimento sustentável e uma agricultura preocupada com o meio ambiente.

A agricultura urbana e periurbana, associada à agricultura orgânica, apresenta alternativas a um cenário mundial que aponta para a intensa urbanização da sociedade. Embora haja intensa controvérsia sobre o tema, tem-se que a agricultura urbana ganha cada vez mais importância nessa discussão.

Outro ponto que merece relevância é que, mesmo ante à importância do tema, percebe-se que o conceito de agricultura urbana ainda se encontra em construção. Seu embasamento envolve diversas variáveis, como características espaciais, econômicas e sociais, entre outras. Como salienta Mougeot (2000), sua principal peculiaridade está associada ao meio em que se insere. A agricultura urbana está integrada ao sistema urbano, o que, por si só, já apresenta diversas dificuldades em razão da complexidade desse meio.

Nesse sentido, estudos da FAO (1999) indicam que a agricultura urbana é uma forma de adaptação ante a falta de separação entre o urbano e o rural, bem como as mudanças ocorridas nos meios urbanos, sobretudo no que diz respeito à expansão física das cidades.

Outra constatação do presente estudo é o fato de que agricultura urbana, a partir de sua inserção no espaço urbano, o qual é moldado pelo capitalismo, a cujos propósitos ela serve, evolui de acordo com a globalização, sendo, também, contraditória. De acordo com Baumann (1999), este processo mundial faz com que a cidade, ou o espaço urbano propriamente dito, acabe perdendo a sua civilidade, na medida em que propicia cada vez mais "ilhados".

De outra banda, destaque-se que, em muitos lugares do mundo, a agricultura familiar vem se tornando alvo da agenda de políticas públicas, como é o caso da Colômbia e também de Cuba, principais referências mundiais citadas em estudos. A importância de sua menção na elaboração da agenda de políticas públicas está na segurança alimentar, mas, sobretudo, no desenvolvimento humano. 
Ferreira e Castilho (2007, p. 12) asseveram que:

Assim sendo, existem várias entidades que desenvolvem ações voltadas ao desenvolvimento desse tipo de agricultura, tais como: PNUD, Organização para Alimentação e a Agricultura das Nações Unidas (FAO), Centro de Recursos para a Agricultura e Silvicultura Urbanas (RUAF), dentre outras. O que há de comum nas políticas destas entidades internacionais é que todas buscam garantir o acesso das populações à alimentação, ou seja, à segurança alimentar sem perder de vista aspectos do desenvolvimento humano sustentável.

Os mesmos autores mencionam que, no Brasil, existem instituições que se dedicam a promover a agricultura urbana, desde ONGs até o Estado em todas as suas instâncias. Eles citam como exemplo o Ministério da Agricultura, que, em 2007, realizou um estudo no sentido de identificar espaços de agricultura urbana e periurbana no sentido de intensificá-las.

Acrescente-se que a agricultura urbana deve ser incentivada não somente nas grandes metrópoles, mas também nas pequenas e médias cidades, as quais vêm demonstrando importância no cenário atual brasileiro, bem como sendo objeto de estudos recentes a respeito das características da urbanização brasileira. Embora existam documentos e estudos a respeito da agricultura urbana, como se mencionará nas considerações finais, eles não apresentam critérios precisos, apresentando apenas questões pontuais, não tratando da temática como um todo.

\section{Considerações finais}

A agricultura urbana, sob o prisma da agroecologia e da agricultura orgânica, exige mobilização e articulação entre diferentes áreas, as quais vão desde a sociedade envolvida até o Estado em todas as suas esferas: União, Estados e Municípios. Após se considerar a questão-problema, o estudo buscou analisar a agricultura urbana e sua relação com a agroecologia e a agricultura orgânica.

As discussões propostas neste estudo confirmam que a agricultura urbana se apresenta como cada vez mais necessária e, também, como uma solução à crescente urbanização, de forma a garantir a segurança alimentar, bem como o desenvolvimento sustentável. Isto é, embora a globalização e seus efeitos se asseverem cada vez mais, a agricultura urbana tem se demonstrado eficaz ao fortalecer regiões.

Por conseguinte, é importante mencionar que as cidades estão em constantes transformações. Se antes os estudos concentravam-se nas grandes metrópoles, atualmente, eles se voltam aos interesses das pequenas e médias cidades, as quais possuem características distintas e dinâmicas diversas, e, da mesma forma, podem abrigar a agricultura urbana.

Cabe ainda destacar que, mesmo havendo interesse de agentes públicos em propagar a agricultura urbana, o que se tem é incipiente. É necessário maior esforço e dedicação dos planejadores urbanos, dos governantes e da sociedade civil. A agricultura urbana é tida como uma das configurações do espaço urbano. 
Dessa forma, essa característica não pode ser desconsiderada pelos planejadores das cidades.

Diante do exposto, confirma-se a hipótese inicial de que a agricultura urbana, no processo mundial de globalização, pode ser útil para o fortalecimento de regiões. Entretanto, tendo em vista a escassez de estudos mais profundos, sua prática ainda é pouco conhecida, ou até mesmo pouco promovida. As vantagens da agricultura urbana vão desde a otimização do espaço cultivável em até $400 \%$, a possibilidade de cultivos em espaços reduzidos, a reutilização de materiais, a produção de alimentos saudáveis, até o aquecimento do comércio local.

Por fim, importa destacar que a implantação da agricultura urbana enfrenta diversos desafios, entre os quais os principais são a superação das fronteiras entre o rural e o urbano, o descaso dos governantes com o tema, a ignorância da sociedade de sua importância para o desenvolvimento sustentável e para o desenvolvimento humano.

Como sugestão para estudos futuros, torna-se importante analisar melhor a relação entre a agricultura urbana e as pequenas e médias cidades, bem como investigar formas de incentivar a agricultura urbana. Ainda, analisar como os atores sociais são decisivos na elaboração, implantação e fiscalização de políticas públicas voltadas ao desenvolvimento da agricultura urbana.

\section{Referências}

ALTIERI, M. A. Agroecologia - A dinâmica produtiva da agricultura sustentável. Porto Alegre: UFRGS, 1998.

AQUINO, Adriana Maria de; ASSIS, Renato Linhares de. Agricultura orgânica em áreas urbanas e periurbanas com base na agroecologia. [Challenges of organic agriculture in urban and suburban areas.] Ambiente \& sociedade, n. 10, v. 1, p. 137-150, 2007. Disponível em: <http://www.scielo.br/scielo.php?script=sci arttext\&pid=S1414-753X2007000100009\&lang=pt>. Acesso em: 5 ago. 2016.

ASSIS, R. L. de; ROMEIRO, A. R. Agroecologia e Agricultura Orgânica: controvérsias e tendências. Desenvolvimento e Meio Ambiente, Curitiba, v. 6, p. 67-80, 2002.

BAUMAN, Z. Globalização: as consequências humanas. Tradução: Marcus Penchel. Rio de Janeiro: Zahar, 1999.

CANUTO, J. C. Agricultura Ecológica en Brasil - Perspectivas socioecológicas. Tese (Doutorado) - Instituto de Sociología y Estudios Campesinos, Escuela Superior de Ingenieros Agrónomos y Montes, Córdoba, 1998.

CAPORAL, Francisco Roberto. Em defesa de um Plano Nacional de Transição Agroecológica: compromisso com as atuais e nosso legado para as gerações futuras. v. 1. Brasília: MDA/SAF, 2009.

CAPORAL, Francisco Roberto; COSTABEBER, José Antônio; PAULUS, Gervásio. Agroecologia como matriz disciplinar para um novo paradigma de desenvolvimento rural. 2004. Disponível em: <http://www.agroecologiaemrede.org.br/upload/ arquivos/P399_2005-11-10_133719_016.pdf>. Acesso em: 5 ago. 2016. 
CIDADES SEM FOME. Disponível em: <http://cidadessemfome.org/pt-br>. Acesso em: 23 maio 2015.

FAO. Cuestiones de la agricultura urbana. Revista Enfoques, 1999. Disponível em: <http://www.fao.org/ag/esp/revista/9901sp2.htm>. Acesso em: 16 set. 2016.

FERREIRA, J. R.; CASTILHO, C. J. M. Agricultura urbana: discutindo algumas das suas engrenagens para debater o tema sob a ótica da análise espacial. Revista de Geografia, Recife, v. 24, n. 2, p. 6-23, 2007. Disponível em: <http://www. revista.ufpe.br/revistageografia/index.php/revista/article/viewFile/111/66>. Acesso em: 5 ago. 2016.

INSTITUTO ECOAÇÃO. Você sabe o que é agricultura periurbana? Disponível em: <http://institutoecoacao.blogspot.com.br/2014/04/voce-sabe-o-que-eagricultura-periurbana.html>. Acesso em: 15 mar. 2015.

MACHADO, A. T.; MACHADO, C. T. Agricultura urbana. Planaltina: Documentos Embrapa Cerrados, 2002.

MARCONI, M. de A.; LAKATOS, E. M. Fundamentos de metodologia científica. 5. ed. São Paulo: Atlas, 2003.

MOUGEOT, L. J. A. Urban agriculture: definition, presence, potential and risks. In: BAKKER, M.; DUBBELING, S.; GÜNDEL, U. Sabel-Koschella; ZEEUW, H. (Eds.). Growing cities, growing food: urban agriculture on the policy agenda. Feldafing: Deutsche Sitffung für Internationale Entwicklung, 2000. p. 1-42.

ORGÁNICOS DE COLOMBIA. Disponível em: <http://www.organicosdecolombia. com/content/agricultura-urbana-org\%C3\%A1nica-organoponia-o-bioponia>. Acesso em: 14 abr. 2015

PENTEADO, S. R. Introdução à Agricultura Orgânica: normas e técnicas de cultivo. Campinas: Grafimagem, 2000.

RODRIGUES, V. L. G. S. Urbanização e ruralidade. Brasília: MDA, 2009.

SANTOS, Boaventura de Sousa. Por uma concepção multicultural de direitos humanos. Revista Crítica de Ciências Sociais, n. 48, p. 11-32, jul. 1997. Disponível em: <http://www.boaventuradesousasantos.pt/media/pdfs/Concepcao_ multicultural_direitos_humanos_RCCS48.PDF>. Acesso em: 5 ago. 2016.

WEID, Jean Marc von der. Agroecologia: Condição para a segurança alimentar. Agriculturas: Experiências em Agroecologia. Rio de Janeiro, v. 1, p. 4-7. Disponível em: <http://aspta.org.br/wp-content/uploads/2011/05/ N\%C3\%BAmero-especial.pdf>. Acesso em: 5 ago. 2016. 